\title{
Early discharge care with ongoing follow-up support may reduce hospital readmissions in COPD
}

\author{
Maria Lawlor' \\ Sinead Kealy' \\ Michelle Agnew' \\ Bettina Korn' \\ Jennifer Quinn' \\ Ciara Cassidy' \\ Bernard Silke ${ }^{2}$ \\ Finbarr O'Connell' \\ Rory O'Donnell' \\ 'Department of Respiratory \\ Medicine, CResT Directorate, \\ St. James' Hospital, Dublin 8, Ireland; \\ ${ }^{2}$ Department of General Internal \\ Medicine, Gems Directorate, \\ St. James' Hospital, Dublin 8, Ireland
}

Correspondence: Rory O'Donnell Department of Respiratory Medicine, CResT Directorate, St. James's Hospital, Dublin, Ireland

Email rodonnell@stjames.ie
Background: Early discharge care and self-management education, although effective in the management of chronic obstructive pulmonary disease (COPD), do not typically reduce hospital re-admission rates for exacerbations of the disease. We hypothesized that a respiratory outreach programme that comprises early discharge care followed by continued rapid-access out-patient support would reduce the need for hospital readmission in these patients.

Methods: Two hundred and forty-six patients, acutely admitted with exacerbations of COPD, were recruited to the respiratory outreach programme that included early discharge care, followup education, telephone support and rapid future access to respiratory out-patient clinics. Sixty of these patients received self-management education also. Emergency department presentations and admission rates were compared at six and 12 months after, compared to prior to, participation in the programme for the same patient cohort.

Results: The frequency of both emergency department presentations and hospital admissions was significantly reduced after participation in the programme.

Conclusions: Provision of a respiratory outreach service that includes early discharge care, followed by education, telephone support and ongoing rapid access to out-patient clinics is associated with reduced readmission rates in COPD patients.

Keywords: COPD management outreach, follow-up, out-patient clinics

\section{Introduction}

Chronic obstructive pulmonary disease (COPD), characterised by progressive, irreversible airways obstruction in smokers, ${ }^{1}$ is the fourth leading cause of death in the western world. ${ }^{2}$ Exacerbations of the disease account for up to one in eight emergency hospital admissions in the UK and recurrent hospitalizations, particularly feared by COPD patients, ${ }^{3,4}$ contribute significantly to disease morbidity. Effective management strategies that have been studied include early discharge/hospital in the home interventions and self-management education. ${ }^{5-10}$ However, with the exception of one self-management programme, ${ }^{11}$ neither intervention has been shown to reduce hospital readmission rates. ${ }^{5,8,10,12,13}$

The Respiratory Department in St. James's Hospital, Dublin provides a nurse and physiotherapist-led respiratory outreach service, with early discharge care, hospital in the home follow up and self-management education for a large inner city COPD population. In addition, for patients admitted to the programme, ongoing telephone support is provided with rapid access to respiratory outpatient clinics for future exacerbations. We performed a retrospective review of acutely admitted COPD patients that were discharged on this programme over a 3-year period. We compared emergency department presentations and hospital readmission rates in the same cohort before and after their participation in the programme. 


\section{Methods}

The study was conducted in St. James Hospital, Dublin. A retrospective review of all patients included in the first 3 years (2002-2005) of the COPD early discharge programme was performed.

\section{Patient recruitment}

Referrals were made by the admitting medical team to the respiratory outreach service, that consists of 3 primary members, a clinical nurse specialist, a clinical specialist physiotherapist and an administrator. Back-up was provided by a medical team consisting of a respiratory registrar and consultant. Patients admitted with an exacerbation of COPD and a length of hospital stay not greater than 4 days were considered.

\section{Subjects}

Patients requiring hospital admission due to the severity of their exacerbation or co-existent medical problems were not considered suitable. Patients were also excluded on a discretionary basis due to poor performance status or inadequate social support.

\section{Inclusion criteria}

- A diagnosis of COPD.

- Length of stay $<4$ days.

- Arterial ph $>7.35$, partial pressure of carbon dioxide $<8.0 \mathrm{kpa}$ and partial pressure of oxygen $>7.3$ on room air (unless on domiciliary oxygen).

- Good performance status and social support.

\section{Exclusion criteria}

- Co-existent medical problem eg, suspected malignancy, pulmonary embolus, cardiac failure.

- Consolidation/effusion on chest X-ray.

- Cognitive impairment or lack of social support.

- Residence beyond the hospital catchment area.

\section{Intervention}

Once accepted, patients were discharged with a prescription and letter to advise their GP they were on the programme. They were visited by the nurse or the physiotherapist at home the day after discharge, with subsequent visits conducted over a 14-day period as required. In addition, contact numbers were provided for patients to avail of telephone support if required. Adjustment of treatment was performed after discussion with the medical team who also reviewed patients that failed to improve in an outpatients setting.
Evening and night cover was provided by patients GPs and the hospital emergency department. All patients were given further follow up appointments to see the team at 6 weeks and 3 months. The following care package was provided to patients post-early discharge;

- Clinical assessment and examination.

- Education regarding their condition and proper use of medication including inhalers and nebulizers.

- Smoking cessation advice.

- Chest physiotherapy.

- Individual home exercise programme.

- Provision of self management plans to suitable patients.

- Contact numbers to reach the early discharge team.

After the first 3-month period, patients were advised to retain the supplied contact numbers for use if they felt a further exacerbation was developing. Under these circumstances they were provided with advice and, if appropriate, a same or next day appointment to see the early discharge team in an outpatient setting. Blood tests, sputum analysis, chest X-ray, and oral antibiotic and steroid treatment were provided if necessary. If admission was required the medical team on call were advised and proceeded to admit the patient.

\section{Control group}

To account for regression for the mean, a control group was compiled of 267 patients that included all patients admitted to St. James' with an index hospitalization in 2004 for an exacerbation of COPD, excluding those accepted to the respiratory outreach service. Admission numbers before and after this index hospitalization were compared to determine whether, in the absence of respiratory outreach intervention, admission rates would tend to decline for this cohort.

\section{Self management education}

A subgroup of 60 patients received formal self management education. These were selected on the basis of a single inclusion criterion; the ability to understand every topic on a list of key concepts relevant to COPD exacerbations. These included symptom monitoring, recognition of an exacerbation and medication use. In practice, at their 6-week follow-up appointment, patients were provided with a list of these topics (outlined in Table 1) and each one was discussed. Those patients who demonstrated an understanding of all the topics on the list were offered self management education. This included disease education and provision of medications to take in the event of an exacerbation including antibiotics, 
Table I Knowledge of COPD assessment. List of topics related to COPD discussed with each patient at their 6 week follow up visit. Patients who demonstrated an understanding of all topics on the list were included for self management education

\begin{tabular}{lll}
\hline Topics & Comment & Topics \\
\hline Dirty sputum & Inhalers \\
Increased cough & Nebulizers \\
Increased SOB & Smoking Cessation \\
Increased wheeze & Role of exercise \\
Chest tightness & Relaxation \\
Decrease in ADL & Vaccines \\
Antibiotics & Avoidance measures \\
Steroids & Emergency \\
Patient understands all topics & \\
Yes $\square$ & \\
No $\square$ & \\
\hline
\end{tabular}

Abbreviations: ADL, activities of daily living; COPD, chronic obstructive pulmonary disease; SOB, shortness of breath.

steroids, bronchodilators, expectorants and nebules. In particular, a written personalized action plan was provided that gave specific instructions as to how to recognize an exacerbation and self-administer medication. In addition a sputum jar was provided and sputum clearance techniques explained. In each case an explanatory letter was sent to the patient's GP and telephone support provided Monday to Friday during office hours.

\section{Outcome measurements}

In the same cohort of patients the number of emergency department presentations and hospital admissions in the 6 month and 1 year period immediately after, compared to immediately prior to inclusion in the respiratory outreach programme was compared.

\section{Data analysis}

Statistical analysis was performed using SPSS version 10.0 (SPSS Inc., Chicago, IL, USA). Medians and interquartile ranges (IQRs) were used as the data were nonnormal.
Comparisons between admissions rates were made using Wilcoxon sign-ranked test for paired data. Ninety-five percent confidence intervals (CIs) for the differences in rates before and after inclusion in the programme at 6 and 12 months were calculated based on Poisson assumptions. These 95\% CIs that are not overlapping indicate statistical significance at the 5\% level. Comparison of the absolute change in admissions between the 60 self management patient subgroup and the remaining 186 patients included in the respiratory outreach programme was performed using the Wilcoxon rank sum test.

\section{Results}

Twelve hundred and forty-one patients were referred to the early discharge programme of whom 246 were accepted. The mean (standard deviation) length of stay was 1.48 (1.7) days and there were 2.4 (1.12) home visits required per patient. Patient characteristics for the group as a whole and the subgroup who went on to receive formal self-management education are outlined in Table 2.

Table 2 Clinical characteristics of patients included in the early discharge programme and the subset that received self-management education. There were no significant differences between the two groups. Values are shown as mean \pm SD

\begin{tabular}{lll}
\hline & Early discharge programme & Self-management education \\
\hline $\mathrm{N}$ & 246 & 60 \\
$\mathrm{Age}$ & $67 \pm 9$ & $69 \pm 9$ \\
$\mathrm{FEV}_{1} \%$ & $50.7 \pm 20.8$ & $50 \pm 21.6$ \\
$\mathrm{FEV}_{1} / \mathrm{FVC}$ & $53.2 \pm 13.8$ & $50.1 \pm 13.6$ \\
$\mathrm{TLCO} \%$ & $52.0 \pm 18.7$ & $53.8 \pm 19.3$ \\
\hline
\end{tabular}

Abbreviations: $\mathrm{FEV}_{1}$, forced expiratory volume in one second; $\mathrm{FVC}$, forced vital capacity; TLCO, functional test for measuring the diffusing capacity of the lungs for carbon monoxide. 
Comparisons of emergency department presentation and hospital admissions before and after inclusion in the respiratory outreach programme are given in Table 3. In the 6-month period immediately post-early discharge 7 of the original 246 patients died. Among the remaining 239 patients, mean emergency department presentations and hospital admissions were reduced $48 \%(\mathrm{p}<0.001)$ and $51 \%(\mathrm{p}<0.001)$, respectively compared to the 6-month period preceding early discharge. By 1 -year post-early discharge, a total of 20 patients had died. Among the remaining 226 patients, mean emergency department presentations and hospital admissions were reduced by $40 \%$ $(\mathrm{p}<0.001)$ and $42 \%(\mathrm{p}<0.001)$, respectively compared to the 1 -year period preceding early discharge.

Comparisons of emergency department presentation and hospital admissions before and after inclusion in the respiratory outreach programme for the 60 patients who also received formal self-management education are given in Table 4. In the 6-month period immediately post-early discharge emergency department presentations and hospital admissions were reduced $62 \%(\mathrm{p}<0.001)$ and $69 \%$ ( $\mathrm{p}<0.001$ ), respectively compared to the 6-month period preceding early discharge. At 1-year post-early discharge, emergency department presentations and hospital admissions were reduced by $61 \%(\mathrm{p}<0.001)$ and $62 \%(\mathrm{p}<0.001)$, respectively compared with the 1 -year period preceding early discharge.

Comparison of the change in emergency department presentations and admissions between the 60 self-management patients and the remaining 186 patients included in the respiratory outreach programme showed no significant difference at 6 or 12 months.

Comparisons of hospital admissions for all COPD patients admitted in 2004, but not included in the respiratory outreach programme, are given in Table 5. There was no reduction in admissions at 6 or 12 months after, compared with prior to, this index hospitalization.

\section{Discussion}

The current study shows that patients enrolled in a respiratory outreach service comprising early discharge care, education, telephone support and rapid-access to respiratory outpatient clinics, with and without self-management education, experience fewer emergency department presentations and hospital readmissions for acute exacerbations of COPD than prior to enrolment.

For patients with COPD, health-related quality of life is related to exacerbation frequency ${ }^{14-16}$ while avoidance of hospital admission is a highly valued outcome. ${ }^{3}$ Early discharge and hospital in the home interventions, widely used in the management of exacerbations, are safe, ${ }^{8}$ cost effective. ${ }^{6,9}$ preferential to patients7 and save hospital bed days. ${ }^{5}$ However, readmission rates for patients in these programmes have not differed to those for patients receiving normal hospital care. ${ }^{5,8,9,12}$ Similarly, although there have been many studies of self-management education in COPD, only one, by Bourbeau and colleagues ${ }^{11}$ has been associated with a significant reduction in hospital readmissions. These results are understandable given that most of the interventions studied were not designed to reduce readmission rates specifically. In many studies, early discharge care addressed the exacerbation only, with interventions that included clinical assessment, blood testing, provision of medication and access to an oxygen concentrator, and patients were subsequently discharged from the service. ${ }^{17}$ Most reported self-management education programmes, meanwhile, did not include self-treatment of exacerbations, therefore a key factor in the prevention of hospital admissions was not examined. ${ }^{18}$ Others, moreover,

Table 3 Comparisons of admissions and emergency department presentations in the 6 month and I year period before and after the early discharge programme.Values are shown as medians and interquartile ranges (IQR)

\begin{tabular}{lllll}
\hline & $\begin{array}{l}\text { 12 months before } \\
\text { early discharge }\end{array}$ & $\begin{array}{l}\text { 6 months before } \\
\text { early discharge }\end{array}$ & $\begin{array}{l}\mathbf{6} \text { months } \\
\text { post-early discharge }\end{array}$ & $\begin{array}{l}\text { I2 months } \\
\text { post-early discharge }\end{array}$ \\
\hline $\mathrm{N}$ & 246 & 246 & 239 & 226 \\
Total Admissions & 462 & 359 & 173 & 264 \\
Rate per patient & 1.88 & 1.45 & 0.72 & 1.16 \\
Median (IQR) admissions per patient & $\mathrm{I}(\mathrm{I}, 2)$ & $\mathrm{I}(\mathrm{I}, 2)$ & $0(0,1)^{*}$ & $0(0,2)^{\dagger}$ \\
Emergency dept presentations & 523 & $40 \mathrm{I}$ & 208 & 309 \\
Emergency dept presentations per patient & 2.1 & 1.63 & 0.87 & 1.36 \\
Median (IQR) emergency dept & $\mathrm{I}(\mathrm{I}, 3)$ & $\mathrm{I}(\mathrm{I}, 2)$ & $0(0,1) *$ & $0(0,2)^{\dagger}$ \\
presentations per patient & & & & \\
\hline
\end{tabular}

Notes: ${ }^{\mathrm{p}}<0.00 \mathrm{I}$ compared to 6 months prior to early discharge; ${ }^{\dagger} \mathrm{p}<0.00 \mathrm{I}$ compared to I year prior to early discharge. 
Table 4 Comparisons of admissions and emergency department presentations in the 6 month and I year period before and after the early discharge programme for those patients receiving additional formal self-management education. Values are shown as median and interquartile ranges (IQR)

\begin{tabular}{lllll}
\hline & $\begin{array}{l}\text { I2 months before } \\
\text { early discharge }\end{array}$ & $\begin{array}{l}\mathbf{6} \text { months before } \\
\text { early discharge }\end{array}$ & $\begin{array}{l}\mathbf{6} \text { months } \\
\text { post-early discharge }\end{array}$ & $\begin{array}{l}\text { I2 months } \\
\text { post-early discharge }\end{array}$ \\
\hline $\mathrm{N}$ & 60 & 60 & 60 & 60 \\
Admissions & 98 & 84 & 26 & 37 \\
Admission rate per patient & 1.63 & 1.4 & 0.43 & $0.6 \mathrm{I}$ \\
Median (IQR) admissions per patient & $\mathrm{I}(\mathrm{I}, 2)$ & $\mathrm{I}(\mathrm{I}, 2)$ & $0(0, \mathrm{I})^{*}$ & $0(0, \mathrm{I})^{\dagger}$ \\
Emergency dept presentations & $\mathrm{I} 07$ & $9 \mathrm{I}$ & 34 & $4 \mathrm{I}$ \\
Emergency dept presentations per patient & $\mathrm{I} .78$ & $\mathrm{I} .5 \mathrm{I}$ & 0.56 & 0.68 \\
Median (IQR) emergency dept & $\mathrm{I}(\mathrm{I}, 2)$ & $\mathrm{I}(\mathrm{I}, 2)$ & $0(0,1)^{*}$ & $0(0,1)^{\dagger}$ \\
presentations per patient & & & & \\
\hline
\end{tabular}

Notes: ${ }^{*} \mathrm{p}<0.001$ compared to 6 months prior to early discharge; ${ }^{\dagger} \mathrm{p}<0.001$ compared to I year prior to early discharge.

did not examine the effect on hospital admissions at all. A Cochrane analysis of 14 such studies concluded that because of the heterogeneity in interventions, study populations, follow-up time, and outcome measures, the data generated was insufficient to form recommendations. ${ }^{18}$

The current study, also, has significant limitations. It was not a randomized control trial, but a retrospective analysis, therefore limiting extrapolation of the results to the COPD population at large and preventing us from drawing conclusions as to whether early discharge care actually reduces readmissions. Features in common with other studies do allow us to speculate regarding factors of possible importance to the observed reduction in admission rates. Patient selection and the timing of recruitment are among these. All participants had been recently admitted and, similar to the study by Bourbeaue and colleagues, ${ }^{11}$ were active presenters to the emergency department with an average rate of 1.8 admissions over the preceding year. In contrast in other self-management studies there were lower preceding admission rates, ${ }^{10,19}$ that would be difficult to further reduce. For example, $20 \%$ of the patients studied by Sridhar and colleagues ${ }^{10}$ had not been admitted at all in the 2 years prior to recruitment. In addition, similar to the work by Bourbeau and colleagues ${ }^{11}$ the current study included both a written management plan to address exacerbations (the vast majority of trials of self-management did not), and a formal exercise programme. Less specifically, the prolonged contact between the patients and the respiratory department could, equally, have been important, as the success of self-management education is believed to be reliant on the accompanying ongoing communication with health care personnel. ${ }^{11}$ In the current study, patient/department contact persisted for at least 3 , and up to 36 , months with a strategy that addressed the exacerbation initially, with after-care that included education and smoking cessation advice, followed by encouragement to contact the department thereafter for support if they experienced further respiratory difficulties. However, which, if any, aspect of the outreach programme's interventions contributed most to reduced readmissions cannot be determined from the results, not only because the study was not designed to examine the impact of the individual interventions, but also because self management education did not significantly reduce admissions compared to the outreach programme on its own.

Table 5 Comparisons of admissions in the 6 month and I year period before and after admission for COPD for those patients admitted in 2004 but not included in the respiratory outreach programme. Values are shown as median and interquartile range (IQR)

\begin{tabular}{lllll}
\hline & $\begin{array}{l}\text { 12 months } \\
\text { before admission }\end{array}$ & $\begin{array}{l}\mathbf{6} \text { months } \\
\text { before admission }\end{array}$ & $\begin{array}{l}\text { 6 months } \\
\text { before admission }\end{array}$ & $\begin{array}{l}12 \text { months } \\
\text { before admission }\end{array}$ \\
\hline $\mathrm{N}$ & 267 & 267 & 259 & 244 \\
Admissions & 139 & 70 & 103 & 165 \\
$\begin{array}{l}\text { Median (IQR) admissions } \\
\text { per patient }\end{array}$ & $0(0, \mathrm{l})$ & $0(0,0)$ & $0(0,1)^{*}$ & $0(0,1)^{\dagger}$
\end{tabular}

Notes: ${ }^{*} \mathrm{p}<0.05$ compared to 6 months prior to early discharge, but showing a significant increase in admissions; ${ }^{\dagger} \mathrm{p}=0.102$ compared to I year prior to early discharge. 
The study's results are potentially confounded by a number of significant biases. The inclusion criteria for early discharge care required patients to have good mobility, social support and performance status without other significant co-morbidities. This well-performing sub-population would be expected to have a better chance of avoiding future admissions. Moreover, the self management subgroup's selection, based on their demonstration of a good disease understanding at a point in time, may itself have mitigated against re-hospitalization. Although it is a before and after investigation, the study fails to take into account possible improvements in treatment for COPD. Although these are unlikely to have had an effect of such magnitude, treatment changes in each subject were not recorded for the purposes of the study and can therefore not be out-ruled as a contributing factor. Notwithstanding the above, the highly significant improvement in admission rates is still noteworthy and supports the possibility that a respiratory outreach programme could modify disease related behaviour in a large COPD population.

\section{Conclusion}

The current study suggests the possibility that provision of a nurse and physiotherapist-led respiratory outreach service comprising early discharge care followed by disease education, telephone support, and rapid access to respiratory outpatient clinics may reduce readmission rates in COPD patients. A randomized control trial of this prolonged approach would be worthwhile to substantiate this hypothesis.

\section{Acknowledgments}

The authors wish to acknowledge the help of the staff of the respiratory assessment unit, St. James's Hospital.

\section{Disclosure}

This work was performed in St. James's Hospital, Dublin, Ireland. None of the authors listed in this manuscript have any financial or other conflicts of interest to disclose.

\section{References}

1. Pauwels RA, Buist AS, Ma P, et al. Global strategy for the diagnosis, management, and prevention of chronic obstructive pulmonary disease: National Heart, Lung, and Blood Institute and World Health Organization Global Initiative for Chronic Obstructive Lung Disease (GOLD): executive summary. Respir Care. 2001;46:798-825.

2. Murray CJ, Lopez AD. Evidence-based health policy-lessons from the Global Burden of Disease Study. Science. 1996;274:740-3.
3. Haughney J, Partridge MR, Vogelmeier C, et al. Exacerbations of COPD: quantifying the patient's perspective using discrete choice modelling. Eur Respir J. 2005;26:623-9.

4. Kessler R, Stahl E, Vogelmeier C, et al. Patient understanding, detection, and experience of COPD exacerbations: an observational, interviewbased study. Chest. 2006;30:133-42.

5. Cotton MM, Bucknall CE, Dagg KD, et al. Early discharge for patients with exacerbations of chronic obstructive pulmonary disease: a randomized controlled trial. Thorax. 2000;55:902-6.

6. Hernandez C, Casas A, Escarrabill J, et al. Home hospitalisation of exacerbated chronic obstructive pulmonary disease patients. Eur Respir J. 2003;21:58-67.

7. Ojoo JC, Moon T, McGlone S, et al. Patient's and carer's preferences in two models of care for acute exacerbations of COPD: results of a randomised controlled trial. Thorax. 2002;57:167-9.

8. Sala E, Alegre L, Carrera M, et al. Supported discharge shortens hospital stay in patients hospitalized because of an exacerbation of COPD. Eur Respir J. 2001;17:1138-42.

9. Skwarska E, Cohen G, Skwarski KM, et al. Randomized controlled trial of supported discharge in patients with exacerbations of chronic obstructive pulmonary disease. Thorax. 2000;55:907-12.

10. Sridhar M, Taylor R, Dawson S, et al. A nurse-led intermediate care package in patients who have been hospitalised with an acute exacerbation of chronic obstructive pulmonary disease. Thorax Med J. 2008;38:334-40.

11. Bourbeau J, Julien M, Maltais F, et al. Reduction of hospital utilization in patients with chronic obstructive pulmonary disease: a disease-specific self-management intervention. Arch Intern Med. 2003;163:585-91.

12. Davies L, Wilkinson M, Bonner S, et al. 2000. "Hospital at home" versus hospital care in patients with exacerbations of chronic obstructive pulmonary disease: prospective randomised controlled trial. $B M J$, $321: 1265-8$.

13. Monninkhof E, van der Valk $P$, van der Palen J, et al. Self-management education for patients with chronic obstructive pulmonary disease: a systematic review. Thorax. 2003;58:394-8.

14. Doll H, Grey-Amante P, Duprat-Lomon I, et al. Quality of life in acute exacerbation of chronic bronchitis: results from a German population study. Respir Med. 2002;96:39-51.

15. Seemungal TA, Donaldson GC, Paul EA, et al. Effect of exacerbation on quality of life in patients with chronic obstructive pulmonary disease. Am J Respir Crit Care Med. 1998;157(5 Pt 1):1418-22.

16. Spencer S, Calverley PM, Burge PS, et al. Impact of preventing exacerbations on deterioration of health status in COPD. Eur Respir J. 2004;23:698-702.

17. Ram FS, Wedzicha JA, Wright J, et al. Hospital at home for patients with acute exacerbations of chronic obstructive pulmonary disease: systematic review of evidence. BMJ. 2004;329:315.

18. Effing T, Monninkhof EM, van der Valk PD, et al. Self-management education for patients with chronic obstructive pulmonary disease. Cochrane Database Syst Rev. 2007;4:CD002990.

19. Monninkhof E, van der Valk P, Schermer T, et al. Economic evaluation of a comprehensive self-management programme in patients with moderate to severe chronic obstructive pulmonary disease. Chron Respir Dis. 2004;1:7-16. 